\title{
Study of asphaltene dispersion and removal for high-asphaltene oil wells
}

\author{
Chen Chaogang', 2, Guo Jixiang ${ }^{1 *}$, An Na ${ }^{1,3}$, Pan Yangqiu ${ }^{3}$, Li Yaguang ${ }^{1}$ and \\ Jiang Qingzhe ${ }^{1}$
}

${ }^{1}$ China University of Petroleum, Beijing 102249, China

${ }^{2}$ Key Laboratory of Shale Gas Exploration, Ministry of Land and Resources, Chongqing Institute of Geology and Mineral Resources, Chongqing 400042, China

${ }^{3}$ Northwest Oilfield Branch Engineering and Technology Institute of Sinopec, Urumchi 830011, China

(C) China University of Petroleum (Beijing) and Springer-Verlag Berlin Heidelberg 2012

\begin{abstract}
Many wellbores are blocked by asphaltene deposits, which lead to production problems in the oilfield development process. In this paper, methods such as elemental analysis, and solvent extraction are adopted for the study of wellbore blockages. The content of organic matter in blockages is higher than $96 \%$ and asphaltene is the main component of the organic matter with n-heptane asphaltene content of $38 \%$. Based on the above analyses, an agent for asphaltene dispersion and removal (named as SDJ) was developed. The performance of the SDJ agent was evaluated, and it was found that the dissolution rate of asphaltene can reach $2.9 \mathrm{mg} \cdot \mathrm{mL}^{-1} \cdot \mathrm{min}^{-1}$ at $60{ }^{\circ} \mathrm{C}$. SDJ agent $(1 \mathrm{wt} \%)$ was added to crude oil with a colloid instability index greater than 0.9 can effectively inhibit asphaltene deposition in the wellbore. By the viscosity method, the dissolution amount of SDJ agent was calculated, and it was found that when the viscosity of the system is around $2,000 \mathrm{mPa} \cdot \mathrm{s}$ (the common viscosity of crude oil), the amount of SDJ agent added to the blockage was at least $96 \mathrm{~g}$ per $100 \mathrm{~g}$ blockages. Therefore, SDJ agent has promising application for dispersion and removal of asphaltene deposition in high-asphaltene wells.
\end{abstract}

Key words: Asphaltenes, asphalthene dispersion and removal, blockages, oil well, evaluation

\section{Introduction}

In general, saturates, aromatics, resins and asphaltenes of crude oil are in thermodynamic balance under reservoir conditions. In actual oilfield operation, the change of physical and chemical conditions in the oil reservoir can destroy the balance of asphaltenes in crude oil, resulting in the flocculation and deposition of asphaltenes, which can cause the blockage of strata, wellbores and production equipment. The blockage of wellbores often results in a decrease or even cessation of crude oil production. It can also increase the load on sucker rods, decrease the efficiency of pumps and even cause pumps to stick. More severely, it may result in well shut-in or well abandonment. All the problems mentioned above have deleterious effects on oilfield development and economic benefits (Leontaritis et al, 1994; Akbarzadeh et al, 2004; Merino-Garcia and Andersen, 2004; Pietraru and Cranb, 2003).

Currently, asphaltene deposits in wellbores are removed by injecting solvents or dispersants into the oil well. The conventional solvents are aromatics: toluene, xylene, etc. in which xylene has the best dissolving effect, but some

*Corresponding author. email: guojx002@163.com Received March 16, 2012 problems have occurred in its application, such as high consumption, high treatment cost, short maintenance time and severe contamination of the environment. In order to solve the blockage by asphaltene deposit in target oil wells and to improve oil production, it is necessary to study asphaltene dispersion and removal. Injecting solvents and dispersants simultaneously into oil well is a direction for removal of asphaltene deposits. The synthesis of an agent for asphaltene dispersion and removal to treat wellbore blockages is presented in this paper.

\section{Experimental}

\subsection{Reagents and instruments}

Reagents: An agent for asphaltene dispersion and removal (named as SDJ, self-made, the details of which was presented in section 3.3); Dispersant (self-made); Benzene (AR); Toluene (AR); Sodium dodecylbenzene sulfonate (AR); Isoamyl alcohol (AR); n-heptane (AR); Blockage (from high-asphaltene wells TH10403CX, TH10316 and Yuqi in Tahe Oilfield, Xinjiang, China); Crude oil samples (from TK1114CX, TH10403CX, TP7 and T739 wells in Tahe Oilfield, Xinjiang, China).

Instruments: Soxhlet extractor (Beijing Glass Instrument 
Factory, China); Muffle furnace (Tianjin Tongda Experiment Furnace Factory, Tianjin, China); Turb 550 turbidity detector (WTW Company, Germany); DV-II+Pro programmable viscometer (Brookfield, USA); ZSX Primus II X-ray fluorescence spectrometer (RIGAKU Company, Japan); ICAP 6300 inductively coupled plasma atomic emission spectrometer (Thermo Electron Corporation, USA), Genesis energy dispersive X-ray spectrometer (EDAX Company,
USA).

\subsection{Experimental methods}

The SDJ agent for dispersion and removal of asphaltene deposits in oil wells mainly includes dispersant, solvents and cosolvent. The SDJ agent has the merits of high boiling point, nonvolatility at normal temperature, low contamination to

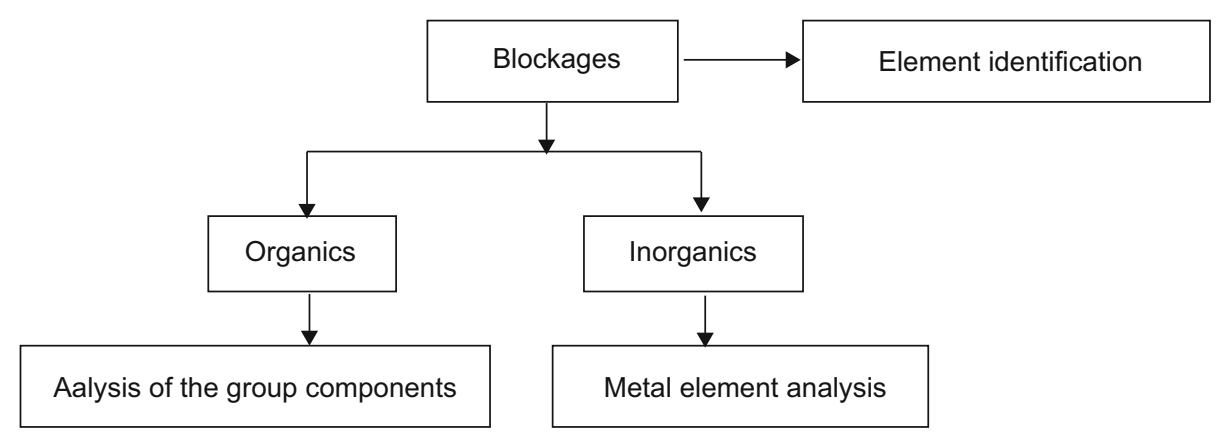

Fig. 1 Analysis of blockage components

environment and lower human toxicity in comparison with benzene.

\subsubsection{Analysis of components of blockage}

Fig. 1 shows the analysis of blockage components. The type of elements in the blockages was determined by an energy dispersive X-ray spectrometer. According to China national standard Analytical method for elements of carbon, hydrogen and oxygen in rock organics (GB/T19143-2003, China), the contents of carbon, hydrogen, sulfur, nitrogen were determined by combustion adsorption analytical method, and oxygen was determined by a splitting method. The contents of organics and inorganics in the blockages were determined by solvent extraction and ashing methods (Del Carmen García et al, 2003). The group components of the organics in the blockage were determined by rod thin layer chromatography. The contents of metal elements in the inorganic fraction of the blockage were determined by inductively coupled plasma emission spectrometry.

\subsubsection{Methods for evaluation of SDJ agent}

Currently, there is not a universal standard for evaluating the performance of dispersion and removal agents, namely their solubility and inhibition performance. Based on the existing evaluation methods (Alboudwarej et al, 2002; Zhao and Yan, 2005; Li et al, 2010), and in consideration of the characteristics of the crude oil and blockages, the following methods are adopted: (1) The method for evaluation of solubility (Li, 2006) was referred to the China's petroleum and natural gas industry standards General specification of paraffin inhibition and removal agent for the use of oil production (SY/T6300-1997, China). Dispersion and removal agent $(10 \mathrm{~mL})$ was added into a beaker and heated at $50{ }^{\circ} \mathrm{C}$ for $15 \mathrm{~min}$. Then $1.00 \mathrm{~g}$ blockage was added to the beaker, and the time needed for complete dispersion and dissolution of the blockage was recorded, and the dissolution rate of the blockage $\left(\mathrm{mg} \cdot \mathrm{mL}^{-1} \cdot \mathrm{min}^{-1}\right)$ was calculated. The dissolution rate was compared with that using benzene. (2) The method for evaluation of inhibition: $1 \mathrm{wt} \%$ SDJ agent and $1 \mathrm{wt} \%$ benzene were added separately to four mixtures of crude oil samples (TK1114CX, TH10403CX, TP7 and T739) with n-heptane. Turbidimetry was used to evaluate the inhibition of SDJ agent with benzene as a control. The turbidity of the system can reflect the circumstance of asphaltene deposition, in addition, the turbidimetry method has high reliability and is free from the effect of oil color.

Method for evaluation of influence of temperature on the solubility of dispersion and removal agent: Excess bulk blockage was added to several beakers at different temperatures, then $10 \mathrm{~mL} \mathrm{SDJ}$ agent was added to each beaker. The time needed for complete dispersion and dissolution of the blockage was recorded, and the dissolution rate $\left(\mathrm{mg} \cdot \mathrm{mL}^{-1} \cdot \mathrm{min}^{-1}\right)$ was calculated. Benzene was used as a control for comparison.

\subsubsection{Determination of the amount of dissolved blockages in SDJ agent}

The possibility of asphalthene deposition was determined by SARA method proposed by Newberry and Barker (Newberry and Barker, 2000). The SARA method is to calculate the colloid instability index (CII) using the following equation.

$$
C I I=\frac{\omega_{\text {saturates }}+\omega_{\text {asphaltenes }}}{\omega_{\text {resins }}+\omega_{\text {aromatics }}}
$$

where $\omega$ stands for the mass fraction of saturates, asphaltene, resins, and aromatics in crude oil respectively.

When the value of $C I I$ for crude oil is greater than or equal to 0.9 , asphalthene deposition is likely to occur (Newberry and Barker, 2000). Therefore, the critical condition for asphaltene deposition is $C I I=0.9$. Because the main components of SDJ agent are aromatics and a small amount of colloid-like substances, the SDJ agent can be 
approximated as resins and aromatics when using Eq. (1). Meanwhile, the maximum amount of dissolved asphalthene in SDJ agent can be considered as a theoretical reference for practical application.

The amount of blockages dissolved in the SDJ agent was determined by the viscosity method. This method is as follows: Excess SDJ agent was added to blockage in a beaker, and kept at $60{ }^{\circ} \mathrm{C}$ for $2 \mathrm{~h}$. Then blockages were added to the system until the viscosity reached to $2,000 \mathrm{mPa} \cdot \mathrm{s}$ at $50{ }^{\circ} \mathrm{C}$. At this time, the total amount of the blockages in the system is the maximum amount of blockages dissolved in SDJ agent. The experiment was repeated with benzene as solvent to determine the maximum amount of blockages dissolved under the same conditions for comparison.

\section{Results and discussion}

\subsection{Appearance of blockages}

The experimental samples were from TH10403CX, TH10316 and Yuqi high-asphaltene wells of Tahe oilfield, China. The blockage from TH10403CX well is a black slaglike substance, which can be powdered mechanically. The blockages from TH10316 and Yuqi asphaltene wells are sticky viscous solids. The appearance of the blockages is shown in Fig. 2. The blockages from Yuqi, TH10403CX and TH10316 wells do not flow when they were heated to $140{ }^{\circ} \mathrm{C}$.

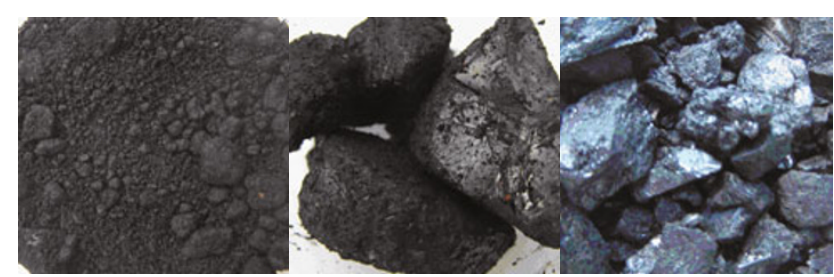

Fig. 2 Appearance of wellbore deposits from TH10403CX, TH10316 and Yuqi wells, Tahe, oilfield, China (from left to right)

\subsection{Analysis of the components of blockage samples}

The type of elements in the blockages was determined by energy dispersive X-ray spectrometer. Hydrogen cannot be detected because the element detection range of EDAX is from $\mathrm{Be}$ to $\mathrm{U}$. The results of the element types in the blockage samples are presented in Table 1.

As shown in Table 1, B, C, N, O, Na, Mg, Al, Si, P, S, Cl, K, $\mathrm{Ca}, \mathrm{V}, \mathrm{Mn}, \mathrm{Fe}, \mathrm{Ni}, \mathrm{Cu}, \mathrm{Zn}, \mathrm{Sr}, \mathrm{Br}$ and $\mathrm{Ba}$ were all detected in the blockage samples. Among these elements, C, N, O, S were the main elements in the blockages.

The results of non-metal elements analysis are shown in Table 2.

The main elements in the blockages are carbon, hydrogen, sulfur and oxygen, and the contents of the four elements are 82.89-83.31 wt $\%, 8.32-9.17 \mathrm{wt} \%, 2.16-3.38 \mathrm{wt} \%$ and $1.84-$ $3.92 \mathrm{wt} \%$ respectively. The $\mathrm{H} / \mathrm{C}$ ratio ranges from 1.21 to 1.33. A low $\mathrm{H} / \mathrm{C}$ ratio means an increase of cyclic structure, aromatic ring structure and unsaturated degree. A certain amount of sulfur, nitrogen and oxygen is in the blockage samples. The oxygen content is closely related to the formation and evolution of heavy oil. Generally speaking, the oxygen compounds in heavy oil can be divided into two types:
One is acidic oxides, such as petroleum acid, naphthenic acid and phenols, and the other is neutral oxygen compounds, such as alcohols, ketones, aldehydes, esters and so on. The groups with sulfur, nitrogen and oxygen are polar groups, and they always show a strong interfacial activity.

The contents of organics and inorganics in asphaltene deposits were determined by solvent extraction and ashing. The results are shown in Table 3.

Table 1 Types of element in the blockage determined by EDX

\begin{tabular}{|c|c|c|c|}
\hline Element type & $\begin{array}{c}\text { TH10403CX } \\
\text { wt } \%\end{array}$ & $\begin{array}{c}\text { TH10316 } \\
\text { wt } \%\end{array}$ & $\begin{array}{c}\text { Yuqi, Tahe } \\
\text { wt } \%\end{array}$ \\
\hline B & - & 5.90 & - \\
\hline $\mathrm{C}$ & 88.40 & 85.50 & 80.80 \\
\hline $\mathrm{N}$ & - & - & 2.45 \\
\hline $\mathrm{O}$ & 4.81 & 3.18 & 7.72 \\
\hline $\mathrm{Na}$ & 0.50 & 0.29 & 0.26 \\
\hline $\mathrm{Mg}$ & 0.04 & 0.02 & 0.05 \\
\hline $\mathrm{Al}$ & 0.11 & 0.04 & 0.33 \\
\hline $\mathrm{Si}$ & 0.33 & 0.07 & 0.55 \\
\hline $\mathrm{P}$ & - & $<0.01$ & $<0.01$ \\
\hline $\mathrm{S}$ & 3.68 & 2.64 & 5.81 \\
\hline $\mathrm{Cl}$ & 1.27 & 1.56 & 0.34 \\
\hline $\mathrm{K}$ & 0.09 & 0.02 & 0.07 \\
\hline $\mathrm{Ca}$ & 0.37 & 0.61 & 0.50 \\
\hline V & 0.01 & 0.06 & 0.12 \\
\hline $\mathrm{Mn}$ & $<0.01$ & - & $<0.01$ \\
\hline $\mathrm{Fe}$ & 0.18 & 0.06 & 0.53 \\
\hline $\mathrm{Ni}$ & 0.02 & 0.01 & 0.02 \\
\hline $\mathrm{Cu}$ & - & - & 0.01 \\
\hline $\mathrm{Zn}$ & 0.02 & $<0.01$ & 0.01 \\
\hline $\mathrm{Sr}$ & $<0.01$ & $<0.01$ & $<0.01$ \\
\hline $\mathrm{Br}$ & $<0.01$ & $<0.01$ & - \\
\hline $\mathrm{Ba}$ & 0.06 & - & 0.45 \\
\hline
\end{tabular}

Note: "_" not detected.

Table 2 Analysis results of non-metal elements in asphaltene deposits

\begin{tabular}{cccccccc}
\hline Samples & $\begin{array}{c}\mathrm{N} \\
\mathrm{wt} \%\end{array}$ & $\begin{array}{c}\mathrm{C} \\
\mathrm{wt} \%\end{array}$ & $\begin{array}{c}\mathrm{H} \\
\mathrm{wt} \%\end{array}$ & $\begin{array}{c}\mathrm{S} \\
\mathrm{wt} \%\end{array}$ & $\begin{array}{c}\mathrm{O} \\
\mathrm{wt} \%\end{array}$ & $\mathrm{H} / \mathrm{C}$ & $\begin{array}{c}\text { Yield } \\
\mathrm{wt} \%\end{array}$ \\
\hline TH10403CX & 0.79 & 82.89 & 9.17 & 2.16 & 3.92 & 1.33 & 98.93 \\
TH10316 & 0.69 & 82.89 & 8.32 & 2.56 & 3.25 & 1.21 & 97.71 \\
Yuqi & 0.71 & 83.31 & 8.91 & 3.38 & 1.84 & 1.28 & 98.15 \\
\hline
\end{tabular}

Table 3 Content of organic and inorganic substances in asphaltene deposits

\begin{tabular}{cccccc}
\hline \multirow{2}{*}{ Samples } & \multicolumn{2}{c}{ Soxhlet extraction method } & & \multicolumn{2}{c}{ Ashing method } \\
\cline { 2 - 3 } \cline { 5 - 6 } & $\begin{array}{c}\text { Content of } \\
\text { organics, wt } \%\end{array}$ & $\begin{array}{c}\text { Content of } \\
\text { inorganics, }\end{array}$ wt $\%$ & & $\begin{array}{c}\text { Content of } \\
\text { organics, wt } \%\end{array}$ & $\begin{array}{c}\text { Content of } \\
\text { inorganics, wt } \%\end{array}$ \\
\hline TH10403CX & 88.73 & 11.27 & & 97.42 & 2.58 \\
TH10316 & 89.50 & 10.50 & & 99.50 & 0.50 \\
Yuqi & 87.91 & 12.09 & & 96.48 & 3.52 \\
\hline
\end{tabular}

As seen in Table 3, the content of inorganics in the three blockage samples is low, the maximum content is $3.52 \mathrm{wt} \%$ by the ashing method. The main component of the blockages is organics. The content of organics determined by ashing method is higher than that by soxhlet extraction method, 
and the reason is that in the soxhlet extraction method the organics cannot be completely extracted from the samples, while in the ashing process the organics in the samples are totally calcined.

The results of group components of organics in the blockage samples are presented in Table 4 .

Table 4 Analysis results of group components in asphaltene deposits

\begin{tabular}{cccccc}
\hline Samples & Saturates, wt $\%$ & Aromatics, wt $\%$ & Resins, wt $\%$ & n-heptane asphaltenes, wt $\%$ & Total amount, wt $\%$ \\
\hline TH10403CX & 28.04 & 21.16 & 12.48 & 38.32 & 100 \\
TH10316 & 26.22 & 19.11 & 13.42 & 41.25 & 100 \\
Yuqi & 26.12 & 20.26 & 13.33 & 40.29 & 100 \\
\hline
\end{tabular}

As seen in Table 4, according to the ratio of the content of saturates $(S)$ to the total content of resins $(R)$ and asphaltenes $(A)$, the ARS blockage (asphaltene-resin-wax deposits blockage) can be divided into three types (Wang, 2003): If $S /(A+R)<1$, the blockage is of asphaltic type; if $S /(A+R)>1$, paraffinic type; and if $S /(A+R)=1$, it is of mixed type. From Table 3 , the $S /(A+R)$ values of the three types are all less than 1 , so they all belong to the asphaltic type. Thus, the study of the dispersion and removal agent should focus on asphaltene dispersion and removal.

The results of metal elements in inorganics are shown in Table 5 .

Table 5 Metal elements content of hydrochloric acid solubles after ashing

\begin{tabular}{ccccccccccc}
\hline \multirow{2}{*}{ Samples } & \multicolumn{1}{c}{ Metal elements contents (mg/g-inorganics) } \\
\cline { 2 - 11 } & $\mathrm{Fe}$ & $\mathrm{Ca}$ & $\mathrm{Mg}$ & $\mathrm{K}$ & $\mathrm{Na}$ & $\mathrm{Cu}$ & $\mathrm{Al}$ & $\mathrm{V}$ & $\mathrm{Ni}$ & $\mathrm{Zn}$ \\
\hline TH10316 & 13.6 & 234.7 & 3.3 & 8.0 & 42.3 & 0.5 & 6.6 & 20.7 & 0.5 & 0.9 \\
TH10403CX & 17.2 & 112.6 & 7.1 & 16.5 & 111.3 & 0.3 & 29.5 & 8.0 & 0.3 & 1.9 \\
Yuqi, Tahe & 106.7 & 98.2 & 7.4 & 3.6 & 12.4 & 3.1 & 5.0 & 17.1 & 0.7 & 2.4 \\
\hline
\end{tabular}

As seen in Table 5, there are high levels of calcium and sodium in the blockage sample from TH10316 and TH10403CX wells, while iron and calcium contents of the Yuqi sample are high. The high iron content is mainly attributed to wellbore corrosion by acidic substances, or iron oxides formed by iron ions in the formation water or crude oil. The high contents of calcium and sodium may be caused by the formation of chloride, carbonate and sulfate in the formation water during the oil production.

By analyzing the types and contents of elements, the contents of organics and inorganics, the group components of the organics, metal elements in the inorganics of the three wellbore blockage samples, it was found that the main elements of the blockages are carbon, hydrogen, oxygen and sulfur, while the contents of other elements are relatively low. The content of organics in the blockages is higher than $96 \%$, and n-heptane asphaltene accounts for $38 \%$ of the organics. The blockage samples belong to asphaltic type.

\subsection{Preparation of the dispersion and removal agent}

Aiming at the properties of the wellbore blockages, a dispersion and removal agent was prepared. This dispersion and removal agent not only can disperse the asphaltenes but also has a strong ability to dissolve the asphaltenes, hence it can stabilize the dispersed asphaltenes and prevent them from re-depositing. When the agent is added into oil wells, it can disperse the asphaltenes, preventing them from aggregating. The agent can also infiltrate into the sheet-like structure of resin and/or asphaltene molecules by forming hydrogen bonds, and partly break up the aggregates of resin and asphaltene molecules, making the structure loose and reducing its degree of order (Guo et al, 2010).

Therefore, design of a dispersion and removal agent should take dispersant, solvent and cosolvent and dissolution rate into consideration, and the properties of the agent should be evaluated by a unified method.

Generally, a surfactant is selected as dispersant (Carnahan et al, 2007). Although it is unable to dissolve the asphaltene, it can disperse the asphaltene in water or oil by surface-active action. The action principle of the dispersant is similar to that of resin, both of them can surround the asphaltene molecules and inhibit the flocculation and deposition of asphaltene.

The choice of solvents should consider such characteristics as high efficiency, environmental-friendliness and low cost (Becker et al, 1992). The main function of solvents is to dissolve dispersant and deposits.

Two solubility parameters $\delta_{1}$ and $\delta_{2}$ proposed by Hildebrand (Liang, 2000) can be used to characterize the solubility of solvents, and their definitions are as follows.

$$
\begin{aligned}
& \delta_{1}=\gamma V^{-1 / \alpha} \\
& \delta_{2}=\left(\frac{\Delta_{\mathrm{r}} H-R T}{V}\right)^{1 / 2}
\end{aligned}
$$

Where $\gamma$ is the surface tension; $V$ is the molecular volume; $\Delta_{\mathrm{r}} \mathrm{H}$ is the heat of vaporization.

Eq. (2) and Eq. (3) show that $\delta_{1}$ and $\delta_{2}$ increase with increasing solvent density, surface tension and heat of vaporization.

When $\delta_{1}>5$, or $\delta_{2}>8$, the solvent has good dissolution ability (Liang, 2000). So the solubility parameters of solvents should be as large as possible, and the solvents should have strong ability to form hydrogen bonds, because there are a large number of hydrogen bonds in the monolayer adsorption of asphaltene on mineral matter. Therefore, besides a high dielectric constant, the solvents should also have strong ability to form hydrogen bonds (Qin and Guo, 2002).

In order to improve the stability of the system, some polar compounds such as alcohols, amines, and ketones (Minssieux, 2001) can be added to the system. 
According to the above mechanism and principles, the dispersion and removal agent was designed with sodium dodecylbenzene sulfonate as dispersant, toluene as solvent, and isoamyl alcohol was used as cosolvent to prevent the re-deposition of asphaltene. The contents of sodium dodecylbenzene sulfonate, toluene and isoamyl alcohol were $10 \mathrm{wt} \%, 37 \mathrm{wt} \%$ and $53 \mathrm{wt} \%$ respectively. The dissolution rate, price, boiling point, flash point and stability should be taken into consideration for the dispersion and removal agent.

\subsection{Evaluation of SDJ agent}

The evaluation results of SDJ agent with the blockages from wells TH10316, TH10403CX and Yuqi are shown in Fig. 3.

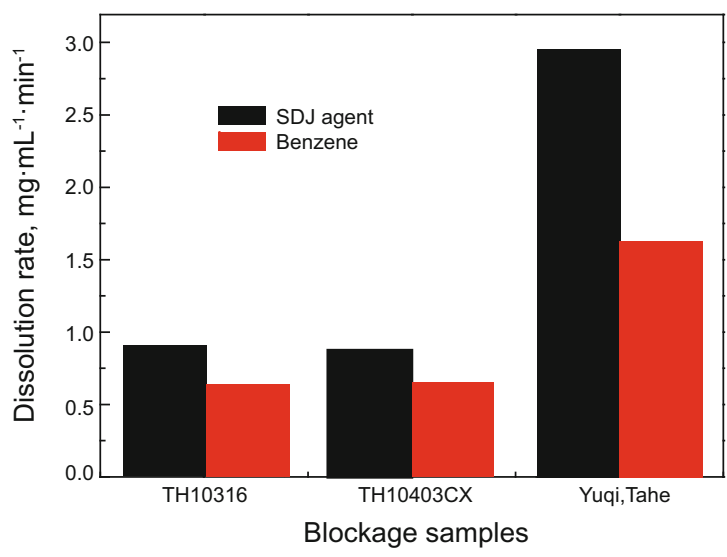

Fig. 3 Dissolution rate of blockage in SDJ agent $\left(60^{\circ} \mathrm{C}\right)$

As seen in Fig. 3, the dissolution rate of blockages in SDJ agent is from $0.87 \mathrm{mg} \cdot \mathrm{mL}^{-1} \cdot \mathrm{min}^{-1}$ to $2.96 \mathrm{mg} \cdot \mathrm{mL}^{-1} \cdot \mathrm{min}^{-1}$, which is higher than that in benzene. The SDJ agent has the highest dissolution rate and the best dissolution effect for the blockage from well Yuqi.

The evaluation results for inhibition performance of SDJ agent with four crude oil samples, which are not stable and the CII of which is lower than 0.9, are shown in the Table 6.
As shown in Table 6, after adding SDJ agent, the turbidity of the system decreased compared with that without SDJ agent and with benzene, indicating that SDJ agent has the effect of inhibiting and reducing asphaltene deposition. When adding n-alkanes to crude oil, the resin is dissolved, causing the flocculation and deposition of asphaltene because of the coalescence of asphaltene molecules. The addition of SDJ agent can prevent the coalescence and deposition of asphaltenes to some extent.

The effect of temperature on the dissolution rate of the blockage in the SDJ agent was studied and the results are shown in Fig. 4.

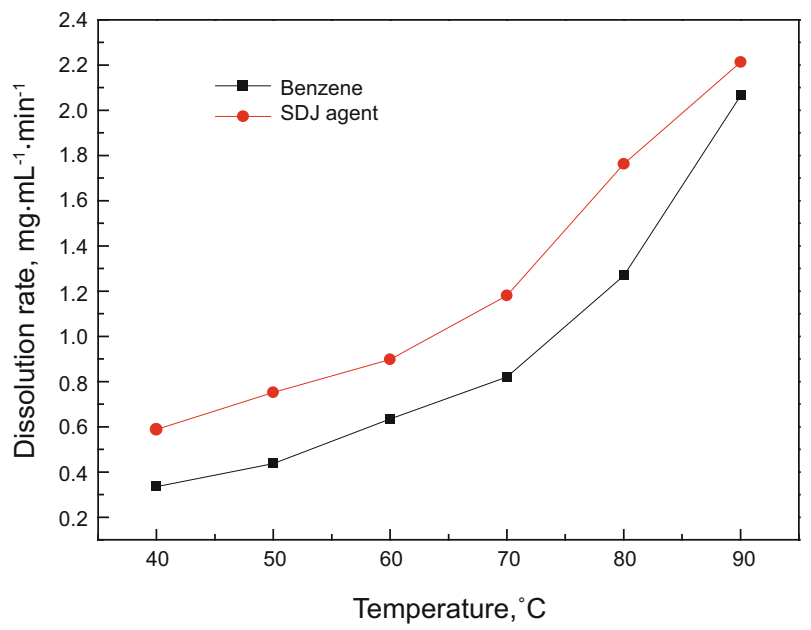

Fig. 4 Effect of temperature on the dissolution rate of TH10316 blockage in SDJ agent

As seen in Fig. 4, the dissolution rate of TH10316 blockage in SDJ agent increased with temperature: It increased slowly from $40{ }^{\circ} \mathrm{C}$ to $70{ }^{\circ} \mathrm{C}$, and rapidly when the temperature is higher than $70{ }^{\circ} \mathrm{C}$, and the dissolution rate reached $2.2 \mathrm{mg} \cdot \mathrm{mL}^{-1} \cdot \mathrm{min}^{-1}$ at $90^{\circ} \mathrm{C}$. This indicated that an increase of temperature can accelerate the dissolution of the blockage. The temperature of the blockages from well

Table 6 Evaluation results for inhibition performance of SDJ agent by the turbidimetric method

\begin{tabular}{ccccc}
\hline Oil Samples & $\begin{array}{c}\text { Ratios of n-heptane to } \\
\text { crude oil }\end{array}$ & $\begin{array}{c}\text { Turbidity, NTU } \\
\text { (without SDJ) }\end{array}$ & $\begin{array}{c}\text { Turbidity, NTU } \\
\text { (with 1 wt\% benzene) }\end{array}$ & $\begin{array}{c}\text { Turbidity, NTU } \\
\text { (with 1 wt\% SDJ agent) }\end{array}$ \\
\hline TK1114CX & $25: 1$ & 56.9 & 55.2 & 53.1 \\
TH10403CX & $50: 1$ & 88.6 & 86.4 & 83.6 \\
TP7 & $80: 1$ & 75.3 & 74.8 & 75.1 \\
T739 & $100: 1$ & 35.2 & 22.3 & 20.2 \\
\hline
\end{tabular}

TH10316 is about $60{ }^{\circ} \mathrm{C}$, and the dissolution rate of TH10316 blockage in SDJ agent is $0.90 \mathrm{mg} \cdot \mathrm{mL}^{-1} \cdot \mathrm{min}^{-1}$ at $60{ }^{\circ} \mathrm{C}$. The dissolution rate of TH10316 blockage in SDJ agent is higher than that in benzene at corresponding temperatures.

\subsection{Amount of dissolved blockages in SDJ agent}

\subsubsection{SARA method}

For the blockages from wells TH10316, TH10403CX and Yuqi, the minimum dosage of SDJ agent for $100 \mathrm{~g}$ blockage can be calculated by the SARA method if the CII of the system equals to 0.9 (stable system). The results are shown in Table 7.

Table 7 The minimum dosage of SDJ agent for $100 \mathrm{~g}$ blockage in the stable system

\begin{tabular}{cc}
\hline Samples & Minimum dosage of SDJ (g/100 g blockage $)$ \\
\hline TH10316 & 42.44 \\
TH10403CX & 40.09 \\
Yuqi, Tahe & 40.19 \\
\hline
\end{tabular}


By the SARA method and the SDJ agent being approximately regarded as resin and aromatics, the minimum amount of SDJ agent for dissolving $100 \mathrm{~g}$ blockage is about $42 \mathrm{~g}$ to obtain a stable system (see Table 7). This is the theoretical minimum dosage of SDJ agent, providing a guide for determination of SDJ agent amount in application.

\subsubsection{Viscosity method}

The relationship of viscosity and temperature for the blockages with SDJ agent and benzene is shown in Fig. 5 and Fig. 6. The amount of SDJ agent required for the blockages of TH10316 and Yuqi can be determined from Fig. 5 and Fig. 6.

As shown in Fig. 5, for the blockage from TH10316, from $40{ }^{\circ} \mathrm{C}$ to $90{ }^{\circ} \mathrm{C}$ the viscosity of the system formed by $12 \mathrm{~g}$ blockage dissolving in $15 \mathrm{~mL}$ benzene is similar to that of $17 \mathrm{~g}$ blockage dissolving in $15 \mathrm{~mL}$ SDJ agent. As seen in Fig. 6, for the blockage from Yuqi when the temperature is greater than $60{ }^{\circ} \mathrm{C}$, the viscosity of the system formed by $25 \mathrm{~g}$ blockage dissolving in $15 \mathrm{~mL}$ benzene is close to that of $25 \mathrm{~g}$ blockage dissolving in $15 \mathrm{~mL}$ SDJ agent.

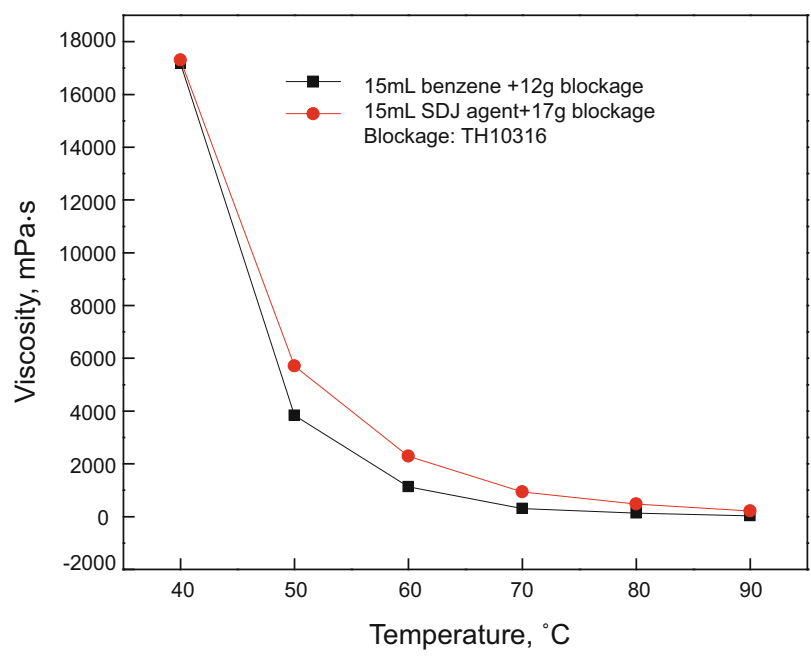

Fig. 5 Relationship of viscosity and temperature for TH10316 blockage with benzene or SDJ agent

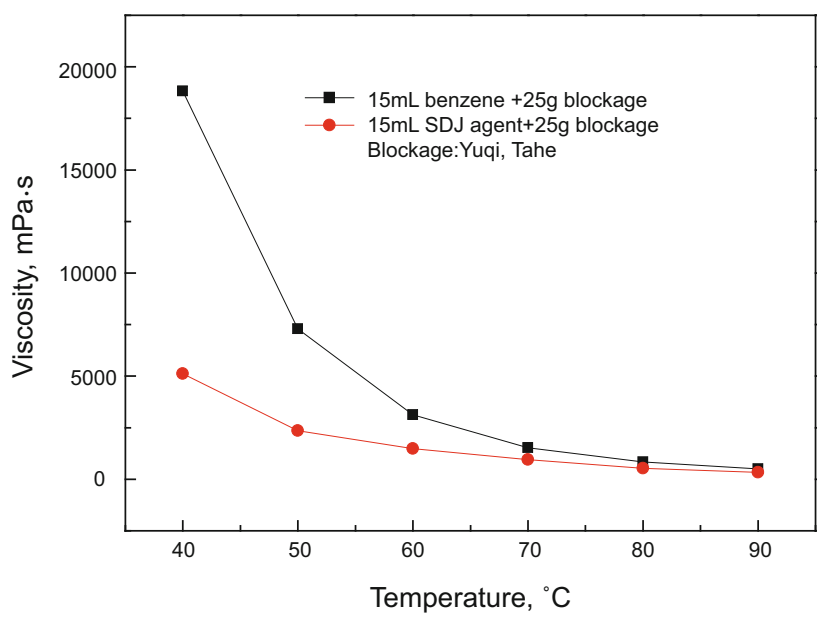

Fig. 6 Relationship of viscosity and temperature for Yuqi blockage with benzene or SDJ agent
The results show that the solubility of SDJ agent is better than that of benzene. In addition, the viscosities of the systems of SDJ agent and blockages of TH10316 or Yuqi are $5710 \mathrm{mPa} \cdot \mathrm{s}$ and $2,360 \mathrm{mPa} \cdot \mathrm{s}$ at $50{ }^{\circ} \mathrm{C}$ respectively, and both of the two systems are flowable. Therefore, the dissolved amounts of SDJ agent for the blockages of TH10316 and Yuqi are $16 \mathrm{~g}$ and $25 \mathrm{~g}$ blockage per $15 \mathrm{~mL}$ SDJ agent respectively. With comprehensive consideration, when the viscosity of the system is $2,000 \mathrm{mPa} \cdot \mathrm{s}$, the dissolved amounts of SDJ agent is about $96 \mathrm{~g}$ per $100 \mathrm{~g}$ blockage.

For wells frequently blocked during normal production, SDJ agent mixed with thin oil can be injected into the wellbore to prevent the formation of asphaltene deposits in the wellbore. When a well has ceased production because of the complete blockage of the wellbore by asphaltene, the SDJ agent can be injected into the wellbore, then the well is shut in for $8 \mathrm{~h}$. Then the blockage in the wellbore dispersed by and dissolved in SDJ, the well can resume production.

\section{Conclusions}

1) The main content of the blockages is organics, which account for more than $96 \mathrm{wt} \%$, and the inorganic matter in the blockages is less than $4 \mathrm{wt} \%$. The main elements of blockages are carbon, hydrogen, sulfur, oxygen, and the contents of the four elements are 82.89-83.31 wt\%, 8.32-9.17 wt\%, 2.16$3.38 \mathrm{wt} \%$ and $1.84-3.92 \mathrm{wt} \%$ respectively, and the $\mathrm{H} / \mathrm{C}$ ratio ranges from 1.21 to 1.33 . The content of $n$-heptane asphaltene in the organics is higher than $38 \%$. The blockages belong to asphaltic type.

2) Preparation of the SDJ agent is aimed at solving the blocking problem in high-asphaltene well. SDJ is composed of sodium dodecylbenzene sulfonate, toluene and isoamyl alcohol, and the amount of sodium dodecylbenzene sulfonate in the agent is $10 \mathrm{wt} \%$. The molecules of the dispersion and removal agent dissolve the blockages well and have the ability to form hydrogen bonds, which can stabilize the dissolved asphaltene and prevent the asphaltene from redepositing.

3) The solubility of asphaltene in the SDJ agent can reach to $2.96 \mathrm{mg} \cdot \mathrm{mL}^{-1} \cdot \mathrm{min}^{-1}$ at $60{ }^{\circ} \mathrm{C}$. The addition of $1 \mathrm{wt} \% \mathrm{SDJ}$ agent to crude oil can effectively inhibit asphaltene deposition in the wellbore, and the solubility and inhibition of the SDJ agent are superior to that of benzene. Furthermore, the contamination to the environment and the human toxicity of the SDJ agent is less than that of benzene, and SDJ agent also has high security and stability.

4) The dissolved amount of SDJ agent was calculated by SRAR method and measured by viscosity method. The result shows that it needs at least $42 \mathrm{~g}$ SDJ agent to dissolve 100 $\mathrm{g}$ blockage to obtain a stable system. When the viscosity of the system reaches to $2,000 \mathrm{mPa} \cdot \mathrm{s}$ at $50{ }^{\circ} \mathrm{C}$, the dissolved amounts of SDJ agent is about $96 \mathrm{~g}$ per $100 \mathrm{~g}$ blockage.

\section{Acknowledgements}

The authors would like to thank the National High Technology Research and Development Program of China (No.SS2013AA060801), National Natural Science 
Foundation of China (No.51274210) and 12th National Science and Technology Major Project of Ministry of Science and Technology of China (No. 20112X05049-003-001-002) for financial support.

\section{References}

Akbarzadeh K, Sabbagh O, Beck J, et al. Asphaltene precipitation from bitumen diluted with n-alkanes. Canadian International Petroleum Conference, June 8-10, 2004, Calgary, Alberta, Canada (Paper 2004026)

Alboudwarej H, Svrcek W Y and Yarranton H W. PVT investigation of asphaltene precipitation and redissolution from bitumens. Canadian International Petroleum Conference, June 11-13, 2002, Calgary, Alberta, Canada (Paper 2002-015)

Becker H L, Thomas D C, Doddridge W R, et al. Asphaltene deposition control using chemical control agents. Petroleum Society of CIM. 7-10 June 1992, Calgary (CIM 92-70)

Carnahan N, Salager J-L and Anton R. Effect of resins on stability of asphaltenes. Offshore Technology Conference. 30 April-3 May 2007, Houston,Texas, U.S.A. (OTC 19002)

Del Carmen García M, Henríquez M and Orta J. Asphaltene deposition prediction and control in a Venezuelan North Monagas Oil Field. SPE International Symposium on Oilfield Chemistry. 5-7 February 2003, Houston (SPE 80262)

Guo J X, Wang H Y, Chen C G, et al. Synthesis and evaluation of an oilsoluble viscosity reducer for heavy oil. Petroleum Science. 2010. 7(4): 536-540

Leontaritis K J, Amaefule J O, Charles R E. A systematic approach for the prevention and treatment of formation damage caused by asphaltene deposition. SPE Production \& Facilities. August 1994.
157-164 (SPE 23810)

Li Y T, Fan D Z, Shi W P, et al. Performance evaluation and field application of a dispersing and plug-removing agent for colloidal bitumen in heavy oil reservoirs. Journal of Xi'an Shiyou University (Natural Science Edition). 2010. 25(2): 51-57 (in Chinese)

Li Z K. Prevention of asphaltene deposition in light oil production wells in district 8 of the Tahe oil field. Oilfield Chemistry. 2006. 23(2): 107110 (in Chinese)

Liang W J. Heavy Oil Chemistry. Beijing: University of Petroleum press. 2000: 18-19 (in Chinese)

Merino-Garcia D and Andersen S I. Thermodynamic characterization of asphaltene-resin interaction by microcalorimetry. Langmuir. 2004. 20(11): 4559-4565

Minssieux. Removal of asphalt deposits by cosolvent squeeze: mechanisms and screening. SPE Journal Mar. 2001. 39-46

Newberry M E and Barker K M. Organic formation damage control and remediation. SPE International Symposium on Formation Damage Control, 23-24 February 2000, Lafayette, Louisiana (SPE 58723)

Pietraru G M and Cranb D T. Changes in asphaltene microenvironments evidenced by fluorescence solvatochromism. Langmuir. 2003. 19(4): 1026-1035

Qin K Z and Guo S H. Petroleum Asphaltene. Beijing: Petroleum Industry Press. 2002. 100-101 (in Chinese)

Wang J. Efficiency of application of asphalt-resin-wax deposit solvents on Bashneft ANK fields. Foreign Oilfield Engineering. 2003. 19(8): 30-31 (in Chinese)

Zhao F L and Yan J N. Evaluation of additives for prevention and removal of asphaltene deposits. Oil Drilling \& Production Technology. 2005. 27(5): 46-48 (in Chinese)

(Edited by Zhu Xiuqin) 